\title{
Psychiatric training in Italy
}

\section{European perspective on the likelihood and difficulties of harmonisation across Europe}

\author{
Lucia Whitney and Janet Bruce
}

We visited Italy in 1995 as part of a National Health Service management learning network. We visited Florence, Prato and Arezzo in Tuscany; before moving on to Rome and Milan. L.W. had completed psychiatric specialist training in Italy, prior to doing so in England.

Many changes have occurred in British psychiatric training, particularly 'Calmanisation', and many changes are occurring in other European countries. The principle aim of these is to standardise and harmonise postgraduate education across Europe, facilitating mutual recognition of qualified specialists. Until recently, however, few attempts have been made to compare training in different parts of Europe; a laudable exception is the European Trainees' Forum (Cornwall \& Sheldon, 1997).

\section{Differences between psychiatric training in Italy and the UK}

Entry examination/selection criteria

Selection in Italy is by both written and oral examinations. Total marks gained at medical school, previous postgraduate qualifications and research work to date are considered.

\section{Organised by individual universities}

There is no national college in Italy, equivalent to the College, to oversee training and set standards. This leads to a wide variation in practice and less cross-fertilisation between different university training centres. Within one region, electroconvulsive therapy may be valued in one centre, but not used in another. Different psychotherapy schools have developed their own traditions in different universities.

\section{No national inspectorate system}

The Health Advisory Service in the UK serve to standardise services. It looks at the structural quality of the service and make recommendations. The Joint Committee on Higher Psychiatric Training also visits and approves training schemes. In Italy there are no equivalent bodies and this allows wide regional variations.

\section{Length of specialist training}

This is four years in Italy compared with a minimum of six years in the UK.

\section{Type of training}

In Italy there is a national syllabus, and six or seven subjects are examined each year. Basic theory covers similar subjects: neuroanatomy, neurophysiology, psychopathology, clinical psychiatry, psychology, social psychiatry, psychotherapies, psychopharmacology. statistics and information technology, etc. Trainees receive 400 hours of teaching each year and spend another 400 hours in clinical work, both inpatient and out-patient. Recently due to pressure to harmonise, schemes have increased the proportion of hours spent in the teaching and supervision of psychotherapy. Wide reading is required. Knowledge of theories from other European traditions is emphasised alongside the Anglo-Saxon model. This is in clear contrast to the limited exposure of UK trainees to other models.

There is a final evaluation which incorporates all examination results. Course work can form an important part of the assessment. The specialist qualification is only granted when this is awarded and an original thesis is presented and discussed.

The trainees are based in the same hospital throughout their training, but modifications, such as community placements are being introduced. On call for trainees, under senior staff supervision, has been introduced recently.

Trainees have limited clinical responsibility. comparable to a British senior house officer (even post-Calman). In the final year there is some increased responsibility, but this still cannot be equated to the duty and role of a UK senior registrar/specialist registrar. 


\section{Sub-specialisations}

In Italy there are no recognised sub-specialities within psychiatric training. At the end of the four years' training the specialist in psychiatry should have gained experience in all aspects of adult psychiatry, including psychotherapy, but none in learning disabilities, substance misuse, child psychiatry or psychogeriatrics.

Organic psychogeriatrics is the province of geriatricians (where available), general physicians or neurologists. Child psychiatry is part of a more general, separate training in child neuro-psychiatry, which lasts four years and which has little cross-fertilisation with general psychiatry. The alcohol and substance misuse services are separate from psychiatry. However, qualified psychiatrists can work in these services. There are no separate provisions for adults with learning disabilities, whereas child neuropsychiatrists offer an excellent service for children with similar difficulties (this appears to be the reverse of UK provision). A UK sub-specialist would not have his accreditation recognised in Italy.

\section{Research}

Students in Italy are strongly encouraged to complete research. Great numbers of articles are published in Italian journals every year. The pressure to produce quantity sometimes takes precedence over quality, as happens in Spain (Cervilla, 1996). The head of the department in psychiatry in Florence believed it was much harder to have articles published in an English language journal, but much more prestigious.

\section{Discussion}

Important changes have been taking place in postgraduate training across Europe in recent years. Many countries, including Britain and Italy, are slowly harmonising, and initiatives such as the European Training Forum are to be welcomed. However, important differences remain. The dilemmas of harmonisation are that gains and losses are implicit in such a process and useful diversity and creativity may be overturned in favour of a mediocre uniformity. The skill in developing European (including UK) training will be to incorporate the best examples.

From a comparison of the British and Italian systems we conclude that UK psychiatrists should develop a better knowledge of other psychiatric traditions and the philosophical position underpinning them. Italian psychiatrists ought to gain greater clinical experience during training, although the much closer supervision inherent in their system protects patients more.

The College system in the UK provides an invaluable way of coordinating training and setting standards, a role we became much more aware of, seeing a system which lacks such a body. Some in this country believe the Royal Medical Colleges are obsolete dinosaurs, providing little value for money, but we would strongly disagree. We would like to see a similar model introduced in Europe (i.e. a European college for psychiatry, to ensure best practice and training is promoted). We believe that UK sub-specialisations are valuable and should be encouraged in Europe.

There continues to be debate over the length of training. Certainly four years in Italy is seen as a requirement for a basic career grade post, not as a training to step into the equivalent of the consultant post as recognised in this country. Recently in Italy the medical hierarchy has been simplified into two career grades only. There are many trainees in Italy, and not all succeed in obtaining a hospital post at the end of their training. Nearly all psychiatrists have a private practice either as their only job or to supplement a hospital post. It will be important to regulate numbers of medical students throughout Europe to meet service requirements but not allow over supply.

\section{Acknowledgement}

This research was funded by the Allan Brooking NHS Travel Fellowship.

\section{References}

Cervilla, J. (1996) Psychiatric training in Spain: is there a need for change? Psychiatric Bulletin, 20, 738-739. CORNWALL, P. L. \& SHELDON, L. (1997) The Fourth European Training Forum. Psychiatric Bulletin. 21, 117.

*Lucia Whitney, Consultant Child and Adolescent Psychiatrist, Riverhead, Goods Road, Belper DE56 1UU; and Janet Bruce, Consultant Psychiatrist, Adult Mental Health, Brandon Mental Health Unit, Leicester General Hospital, Leicester

*Correspondence 